\title{
PREVENÇÃO E IMPUTABILIDADE ABSOLUTA: NOVOS PARADIGMAS DA RESPONSABILIDADE CIVIL NO BRASIL
}

Resumo: Problema: em resposta à nova realidade produtora de danos da sociedade de risco, foram desenvolvidos instrumentos para garantir o direito de não mais ser vítima de certos danos, bem como para assegurar que, mesmo diante de danos que não foram causados injustamente, mas foram injustamente sofridos, haja a tutela adequada e efetiva dos direitos da vítima. Hipótese: a responsabilidade civil apresenta, hoje, uma vertente preventiva, distinta da reprimenda a posteriori que tem como fim precípuo a reparação de um dano já integralmente consumado; e um agravamento da vertente reparadora, simbolizado sobretudo pela teoria do risco integral, que pressupõe, mediante releitura do nexo de causalidade, a internalização dos riscos conexos à atividade de risco intolerável.

Palavras-chave: Sociedade de risco. Responsabilidade civil. Prevenção. Risco integral. Imputabilidade absoluta.

\section{PREVENTION AND ABSOLUTE IMPUTABILITY: NEW PARADIGMS OF CIVIL LIABILITY IN BRAZIL}

\begin{abstract}
Problem: in response to the new damage producing reality of risk society, judicial instruments have been developed to guarantee the right to no longer be a victim of certain damages, as well as to ensure that, even in the case of damages that have not been unjustly caused but have been unjustly suffered, there is adequate and effective protection of the victim's rights. Hypothesis: civil liability today presents a preventive aspect, distinct from the a posteriori reprimand that has as its main objective the reparation of damage already fully consummated; and an aggravation of the reparatory aspect, symbolized above all by the theory of integral risk, which presupposes, through a re-reading of the causal link, the internalization of the risks connected to the activity of intolerable risk.
\end{abstract}

Keywords: Risk society. Civil liability. Prevention. Integral risk. Absolute imputability.

\section{Introdução}

A problemática deste trabalho envolve a ideia de "sociedade de risco", desenvolvida por Ulrich Beck em meados dos anos 1980. Trata-se de uma nova realidade produtora de danos, os quais decorrem da influência do progresso científico e tecnológico sobre o cotidiano dos indivíduos. O problema identificado é o seguinte: em resposta a essa nova realidade, a literatura jurídica e os tribunais procuraram desenvolver instrumentos para garantir o direito de não mais ser vítima de certos danos, bem como para assegurar que, mesmo diante de danos

\footnotetext{
${ }^{1}$ Mestrando em direito processual e bacharel em direito pela Universidade Federal do Espírito Santo (Ufes). Advogado. E-mail: lorenzo.cm@hotmail.com.
} 
que não foram causados injustamente, mas foram injustamente sofridos, houvesse a tutela adequada e efetiva dos direitos da vítima.

Tem-se, como hipótese, que a responsabilidade civil parece se transformar em relação às suas funções tradicionais, apresentando, contemporaneamente, (i) uma vertente preventiva, distante da reprimenda a posteriori que tem como fim precípuo a reparação de um dano já integralmente consumado, e perquirindo, assim, uma tutela positiva ex ante; e (ii) um agravamento da vertente reparadora, simbolizado sobretudo pela teoria do risco integral, que pressupõe, mediante releitura do nexo de causalidade, a internalização dos riscos conexos à atividade de risco intolerável.

Esta pesquisa revisou a literatura jurídica brasileira sobre o tema da responsabilidade civil, bem como abordou casos julgados pelo Superior Tribunal de Justiça e pelos Tribunais de Justiça dos Estados de São Paulo, Minas Gerais e Espírito Santo, a fim de demonstrar a aplicabilidade da conclusão a que chegou.

Sendo assim, as investigações foram de caráter qualitativo e o método utilizado foi o indutivo, buscando estabelecer uma referência geral com base no conhecimento de certo número de dados singulares, ou seja, partindo de dados singulares para a elaboração de uma conclusão de cunho genérico.

\section{A sociedade de riscos e a responsabilidade civil em suas funções clássicas}

Ulrich Beck constatou que a sociedade pós-industrial — ou ao menos o estágio civilizacional transitório à época de sua obra, entre a sociedade industrial clássica e a sociedade de riscos (FALBO; KELLER, 2015, p. 1.995-1.996) — passou a ser regida pela incerteza e pelo "medo", inerentes ao progresso tecnológico experimentado no último século. Se, antes, acreditava-se existir certo controle sobre os efeitos do desenvolvimento científico das populações, incidentes envolvendo tecnologias inovadoras - como a nuclear mostraram o oposto.

Nasceu, assim, a expressão "sociedade de risco", cunhado no lançamento de “Risikogesellschaf”, em 1986. Trata-se de uma estrutura social que lida sistematicamente com perigos e inseguranças induzidas e introduzidas pela própria modernização, tendo como questão central a mitigação das ameaças e riscos criados de modo a não comprometer o processo de modernização, além de não romper a barreira do que seja socialmente suportável (BECK, 2011, p. 23-24). 
O risco pressupõe decisões contendo um mínimo de previsibilidade quanto às suas consequências (o "risco calculado"). A novidade da sociedade de risco, porém, repousa no fato de que as decisões envolvem perigos e sequelas globais, contradizendo a linguagem institucionalizada do controle - e mesmo a promessa de controle - que é irradiada ao público na eventualidade de uma catástrofe. É ampliada a diferença global entre a linguagem de riscos quantificáveis, na qual a sociedade pensa e age, e o mundo de insegurança igualmente criado pelas pessoas. ${ }^{2}$

Inaugurada a novel dinâmica de riscos e, inevitavelmente, de danos aos quais os indivíduos estão sujeitos, a responsabilidade civil assume posição de peculiar relevância nos estudos da ciência jurídica; afinal, na linha do afirmado por Boris Starck (1947, p. 5), “a reparação dos danos que a atividade dos homens causa aos outros homens consiste no problema central do Direito contemporâneo". 3 Porém, preteritamente à atual transição experimentada pelo instituto com fins de se adequar à realidade da sociedade de risco, foi sob a ideia de uma tutela ressarcitória e inibitória, a partir de um prisma retrospectivo do dano i.e., destinada a agir após a consumação do dano — que a responsabilidade civil apresentou três funções clássicas, desenvolvidas desde os primórdios romanos: ${ }^{4}$ a reparatória englobando eventual subdivisão entre compensatória e indenizatória —, a sancionatória e a dissuasória.

A primeira consiste no valor fundamental da responsabilidade civil (NORONHA, 2013, p. 60), encarregado de superar o "direito de vingança" e, assim, de deslocar o caráter punitivo da resposta ao ilícito para o poder público, o que aparta a responsabilidade civil com enfoque na reparação — da responsabilidade penal — voltada à punição ou à censura (SANTOLIM, 2014, p. 8.455; ALMEIDA COSTA, 2000, p. 471-477). A obrigação de reparar o dano faz com que a responsabilidade não tome como medida, a princípio, a gravidade da conduta do lesante ou demais fatores subjetivos, mas unicamente a extensão do dano causado (NORONHA, 2014, p. 460), conforme o caput do art. 944 do Código Civil. A

\footnotetext{
2 Entrevista concedida por Ulrich Beck à "IHU online", vinculada à UNISINOS. Disponível em: http://www.ihuonline.unisinos.br/media/pdf/IHUOnlineEdicao181.pdf.

3 "La réparation des dommages que l'activité des hommes cause aux autres hommes constitue le probleme central du droit contemporain".

${ }^{4}$ Ainda que autores identifiquem elementos sólidos em diplomas como o Código de Hamurabi, são nas codificações romanas que o tema da responsabilidade civil ganha sistematização e paradigmas condizentes com o ordenamento contemporâneo de boa parte do mundo ocidental. Ver PEREIRA, Caio Mário da Silva. Responsabilidade civil. 12a ed., Rio de Janeiro: Forense, 2018, p. 10-14; LIMA, Alvino. Culpa e risco. $2^{\mathrm{a}}$ ed., São Paulo: Revista dos Tribunais, 1998, p. 18-19.
} 
função reparadora está essencialmente voltada a uma abordagem retrospectiva, i.e.: uma vez verificado o dano, busca-se compensá-lo ou indenizá-lo (DIAS, 1983, p. 806) nos limites da sua extensão, pois o objetivo não é outro senão o da reposição do estado de coisas que existia anteriormente ao próprio dano (SANTOLIM, 2014, p. 8.456) - i.e., o retorno ao status quo ante.

Já a função sancionatória ou punitiva, praticada em ordenamentos jurídicos de tradição common law desde meados do século XVIII — embora remonte ao século XIII com a “indenização múltipla”, na qual o lesante era sancionado com a imposição de reparação equivalente a um múltiplo do valor da lesão causada à vítima, que poderia se valer de ação civil para esse fim (VAZ, 2009, p. 41) —, intenta censurar o lesante "por alguma conduta praticada que ofenda gravemente o sentimento ético-jurídico prevalecente em determinada comunidade", como na hipótese de se impor o pagamento de quantia pecuniária aos familiares de uma vítima de homicídio (FACCHINI NETO, 2003, p. 163 apud VAZ, 2009, p. 76).

Fernando Noronha (2014, p. 461-462 e 533-534) traça um paralelo necessário entre a função punitiva e a responsabilidade criminal, assemelhando aquela a uma "pena privada" de caráter retributivo, ou seja, que busca retribuir o ilícito com um castigo proporcional, conferindo um caráter meramente acessório a esse fim na esfera civil. Ademais, toma como principal exemplo a responsabilidade civil sobre danos puramente anímicos (ou morais em sentido estrito) ou puramente corporais, quando "resta patente a finalidade de punição ao lesante, sobretudo se agiu com forte culpa", vez que danos dessa estirpe não são passíveis de reparação em sentido estrito.

No mesmo sentido, Judith Martins-Costa e Mariana Pargendler (2005, p. 16) destacam a função punitiva da responsabilidade civil em situações de dano extrapatrimonial, valendo-se da evolução do instituto na tradição anglo-saxã:

Verifica-se, com efeito, um certo paralelo com o surgimento - mas apenas com o surgimento - da doutrina dos punitive damages na tradição anglo-saxônica. Como vimos, diante da impossibilidade originária em ressarcir o dano que não deixasse lastros patrimoniais, lançou-se mão da teoria punitiva a fim de não deixar o lesado, nesses casos, sem qualquer amparo por parte do ordenamento jurídica. No entanto, uma vez consagrada a reparabilidade do dano moral, a função da indenização passou a ser entendida como meramente compensatória, perdendo, assim, sua primitiva vinculação com o instituto dos punitive damages. Estes, por sua vez, passaram a ser concedidos somente nos casos excepcionais em que o estado subjetivo do causador do dano, aliado à alta censurabilidade de sua conduta, justificasse a fixação do quantum indenizatório em patamar superior ao necessária para a mera compensação (...). Similar trajeto não se reflete na doutrina e na jurisprudência brasileiras, que 
continuam a conotar aspectos punitivos como "imanentes" ou próprios aos danos morais, reforçando-se a tese punitiva que não foi suplantada sequer pela indenizabilidade irrestrita do dano moral pela Constituição de 1988.

De todo modo, percebe-se que a função punitiva guarda estreita relação com elementos subjetivos, tal qual o grau de culpa ou a própria reprovabilidade da conduta - o que a difere da função reparatória, que pretende precipuamente o ressarcimento na exata extensão do dano sofrido. Inclusive, embora a função sancionatória usualmente justifique o agravamento da obrigação de indenizar, tem também o condão de produzir efeito contrário, como na hipótese do parágrafo único do art. 944 do Código Civil, que permite ao juízo diminuir equitativamente a indenização em casos com grandes danos e reduzida culpa do responsável (NORONHA, 2014, p. 463).

Por fim, a função dissuasória se diferencia da punitiva por levar em consideração não uma conduta passada, mas por procurar dissuadir condutas futuras. $O$ adequado funcionamento dos mecanismos de responsabilidade civil "funciona como sinalização, seja para aquele que é reconhecido como o causador do dano, seja para terceiros, acerca das consequências do ato praticado, dissuadindo-os quanto a uma eventual recorrência" (SANTOLIM, 2014, p. 8.458). A função dissuasória faz com que a responsabilidade tome por objetivo uma prevenção geral de dissuasão ou de orientação sobre condutas a adotar - uma prevenção empreendida a partir de lesões já consumadas, i.e., uma tutela negativa inibitória —, tendo como meio a condenação à reparação ou compensação dos danos provocados (FACCHINI NETO, 2003, p. 164 apud VAZ, 2009, p. 76).

Muito bem. Em razão da complexidade econômica e tecnológica na qual a sociedade se encontra imersa, passou-se a não ser sempre tarefa simples delimitar o responsável pelas reparações, ou mesmo viabilizar a reparação, considerando uma possível insuficiência de recursos ou até a irrecuperabilidade do bem jurídico afetado. Atilio Anibal Alterini (1974, p. 20), v.g., pontua que "todos são passíveis de sofrer um dano, mas nem sempre esse dano é ressarcível. A ressarcibilidade do dano principia por pressupor que seja juridicamente atribuível a outro sujeito; e tem um limite objetivo que o circunscreve em quanto reparável”. E isso tem feito com que a responsabilidade civil passe por uma revisão crítica de suas estruturas e funções, trazendo questionamentos não só acerca da melhor forma de reparar os danos, "mas também o dilema sobre se repará-los é efetivamente a melhor solução" (SCHREIBER, 2012, p. 226). 
Nesse sentido, a ordem jurídica acaba por gradativamente reconhecer outros instrumentos, diversos da responsabilidade civil em suas funções clássicas, para serem opostos aos danos injustos e, dessarte, manejarem os crescentes e inéditos riscos exsurgidos no meio social. Tais instrumentos, cujo escopo é evitar situações potencialmente lesivas a interesses fundadas em valores jurídicos, englobam sobretudo os mecanismos de prevenção, precaução e risk management, que promovem uma tutela preventiva positiva com vista à máxima proteção dos direitos.

\section{Responsabilidade civil como tutela preventiva positiva}

Como afirmado no introito, o aspecto preventivo da responsabilidade civil tem por objeto uma tutela positiva ex ante, em vez de uma reprimenda a posteriori do dano já integralmente consumado. Para se admitir esse raciocínio, devem ser adotadas duas premissas:

(i) a indenização pecuniária, enquanto reparação ao desfalque patrimonial sofrido, ou enquanto compensação que busca equivaler à lesão extrapatrimonial suportada (SANSEVERINO, 2010, p. 58), é apenas uma face da função reparatória. Logo, não se pode ter a responsabilidade civil restrita à ideia de eficácia indenizatória, conforme defende autorizada doutrina (ALBUQUERQUE JR., 2016, p. 96-99), pois seriam excluídas do âmbito de aplicação da matéria obrigações de fazer e de não fazer que consistem em reparações in natura. Um exemplo recente da aceitação dessa premissa é o Enunciado no 589 do Conselho da Justiça Federal, elaborado na VII Jornada de Direito Civil: “a compensação pecuniária não é o único modo de reparar o dano extrapatrimonial, sendo admitida a reparação in natura, na forma de retratação pública ou outro meio", assinalando como justificativa que "não há, no Código Civil, norma que imponha a indenização pecuniária como meio exclusivo para reparação do dano extrapatrimonial";

(ii) o risco é um dano potencial ou um dano com certo grau de consumação, dados os abalos individuais ou sociais provocados pelo ato de potencial lesivo intolerável, conquanto tal potencial não tenha se realizado plenamente. Mostra-se viável, assim, a responsabilização sem a existência completa de dano, considerando que um ato pode produzir turbação com consequências jurídicas mais concretas, sem, contudo, 
apresentar todas as características do fato danoso ressarcível (SINTEZ, 2011, p. 450452 apud CARRÁ, 2019).

Passa-se, então, à análise dos mecanismos de prevenção, precaução e risk management. O princípio da prevenção é evocado quando o risco de dano é atual, concreto e real; em verdade, quando o risco já se mostra um perigo, o qual, segundo Tereza Ancona Lopez (2010, p. 1.225), trata-se do risco conhecido, tomando como exemplos o limite de velocidade nas estradas e os exames prévios a uma intervenção cirúrgica.

Já o princípio da precaução (Vorsogeprinzip) supõe a Vorsoge como algo além de um simples cuidado, devendo ser observada em situações de riscos hipotéticos que têm o condão de levar a danos de considerável gravidade (LOPEZ, 2010, p. 1.226). Tal "percepção do risco" tem de ser construída a partir de evidências científicas — perícias, estatísticas e estudos de impacto sociocultural —, não se ignorando a incerteza quanto à periculosidade da atividade, de acordo com Philippe Kourilsky e Geneviève Viney (2000, p. 20-21):

Le meilleure gestion de la perception des risques, qui constitue à la fois un élément de bien être social et souvent une condition de l'efficacité des mesures prices par les décideurs, ne doit pas être négligé. Toutefois, la dimension politique associée a la perception des riques ne devrait pas peser excessivement sur l'action, ni en dévoyer le sens, ni conduire à des décisions d'un coût social desproporcionné. Il fault afirmee clairement que l'objectif principal du princip de précaution est bien de diminuer les risques.

Glenda Gonçalves Gobim (2015, p. 200-201), v.g., cita julgado do Tribunal Regional Federal da $2^{\text {a }}$ Região que decidiu por suspender as atividades de uma mineradora no Estado do Espírito Santo, diante da ameaça de danos incalculáveis e irreversíveis que advinha do exercício de suas atividades. ${ }^{5}$

No mesmo sentido e mais recentemente, vê-se o risk management como técnica que, somada aos fins reparadores da responsabilidade civil, procura delimitar os pontos de risco em cada estrutura organizada e eliminá-los antes da ocorrência de outros potenciais danos (SCHREIBER, 2012, p. 226). Giulio Ponzanelli (2003, p. 430) cita a responsabilidade médica e aponta como a extinção de fatores perigosos dentro da estrutura hospitalar — v.g., tecnologias obsoletas ou condições precárias do maquinário, turnos irrazoáveis de trabalho e ausência de comunicação entre os funcionários — pode prevenir a deterioração do quadro e a

\footnotetext{
5 TRF-2 - AI n ${ }^{\circ}$ 0015075-43.2007.4.02.0000, Rel. Des. Frederico Gueiros, 6 a Turma, Data de Julgamento: 25.10.2010.
} 
ocorrência de danos mais graves, em vez de simplesmente imputar-se uma condenação pecuniária ao hospital por deficiências organizacionais.

Tomando-se esses três mecanismos, conclui-se que a possibilidade de vir a ocorrer o dano, em detrimento de uma certeza científica, é satisfatoriamente apta a ensejar intervenções judiciais ou administrativas (WEDY, 2014, p. 269). Isso é possível no âmbito do direito público, em que o poder de polícia de órgãos como o Conselho Administrativo de Defesa Econômica (Cade), a Comissão de Valores Mobiliários (CVM) (SCHREIBER, 2012, p. 227) e a Agência Nacional de Vigilância Sanitária (Anvisa) promove a ordenação social e econômica por meio de prescrições e induções, objetivando a conformação da liberdade e da propriedade às possibilidades e aos limites estabelecidos em lei (BINENBOJM, 2017, p. 6770); e, ainda, no contexto do direito privado, tal como em casos relacionados ao direito de vizinhança e ao direito à intimidade. Eis alguns exemplos:

(i) recalls de automóveis e outros bens de consumo, promovidos assim que as fábricas de origem identificam peças, softwares ou outros itens defeituosos após disponibilização do bem no mercado, algo que vai além de um mero direito consumerista decorrente da responsabilidade contratual - afinal, o potencial danoso desse fato supera, em muito, os possíveis danos já consumados, tais como perda de vida útil ou de qualidade do produto, abalo na credibilidade do mercado afetado pelo recall perante a população e as instituições etc.;

(ii) os direitos de vizinhança, que limitam propriedade — ou qualquer situação jurídica que envolva titularidade de direito real - no intuito de resguardar ex ante direitos como salubridade, segurança e sossego (incisos II, III e IV do art. 1.336 do Código Civil). A ação de dano infecto é o instrumento processual típico pelo qual o proprietário ou o possuidor de um prédio pleiteia a cessação da má utilização da propriedade vizinha, podendo ser manejada já em um cenário de risco iminente aos sobreditos bens jurídicos. Tem-se, ainda, a ação de nunciação de obra nova, que compete a quem pretende impedir que o prédio de sua propriedade, ou posse, seja prejudicado em sua natureza, substância, servidão ou fins por obra nova em prédio vizinho, requerendo-se o embargo desta, a sua suspensão e, enfim, a sua demolição à custa do nunciado (GIANESINI, 1993, p. 12-13 e 25-26); ${ }^{6}$

\footnotetext{
${ }^{6}$ É mister que a obra nova tenha sido iniciada, mas não esteja concluída. Cabível, pois, a ideia de se evitar um dano ainda não plenamente consumado, que pode produzir turbação com consequências jurídicas mais concretas.
} 
(iii) obrigação de não-fazer imputada ao autor de uma obra manifestamente difamatória antes de sua publicação, com fins de preservação da imagem e da honra do biografado - algo dificilmente reparável após o escárnio público, sobretudo diante da disseminação de notícias em tempo real (GODIM, 2015, p. 201).

Já no que toca ao direito público, são exemplos vivenciados recentemente pela coletividade:

(i) com amparo na Lei $\mathrm{n}^{\circ}$ 8.069/90, membros do Ministério Público e do Judiciário têm determinado a vacinação obrigatória de menores em surtos de doenças contagiosas, ${ }^{7}$ como sarampo e caxumba;

(ii) a Anvisa, junto ao Ministério da Saúde e ao Ministério da Agricultura, Pecuária e Abastecimento, periodicamente edita normas técnicas sobre a produção e a comercialização de vacinas em humanos e animais, ${ }^{8}$ exercendo em seguida atividade fiscalizatória, com eventual aplicação de multa e outras sanções, a fim de prevenir danos à saúde da população e à própria economia;

(iii) monitoramento de agrotóxicos e de organismos geneticamente modificados (OGM's) por parte dos órgãos governamentais encarregados da liberação e da fiscalização posterior dos produtos (LOPEZ, 2010, p. 1.227).

Portanto, o atual momento da teoria da responsabilidade civil, i.e., a realidade da sociedade de riscos, detecta uma preocupação crescente "no sentido de ser garantido o direito de alguém de não mais ser vítima de danos. Este caráter de prevenção da ocorrência de danos busca seu espaço no sistema de responsabilidade civil, em paralelo ao espaço sempre ocupado pela reparação dos danos já ocorridos”(HIRONAKA, 2007, p. 34).

\section{O risco integral e sua relação com a sociedade de riscos: a coexistência da prevenção com a imputação absoluta}

A função preventiva da responsabilidade civil deve funcionar ao lado da responsabilidade em suas funções tradicionais. Uma não exclui a outra, mostrando-se ambas insubstituíveis diante da sempre presente possibilidade de o dano não conseguir ser evitado (LOPEZ, 2010, p. 1.231) — ou seja, diante da existência do risco residual (KOURILSKY;

\footnotetext{
${ }^{7}$ OFÍCIO-CIRCULAR N ${ }^{\circ}$ 12/2018/PFDC/MPF, Brasília-DF, 5 de julho de 2018.

8 "Manual de normas e procedimentos para vacinação" - 1 1a ed., 2014, Ministério da Saúde; "Orientações para fiscalização do comércio de vacinas contra a febre aftosa e para controle e avaliação das etapas de vacinação" Agosto de 2005, Ministério da Agricultura, Pecuária e Abastecimento.
} 
VINEY, 2000, p. 21). Consumado o dano, deverá ser reparado integralmente por seu autor ou por um seguro, seja a seguridade social ou um seguro privado, esse último no âmbito dos mecanismos que "promovem, paralelamente aos remédios tradicionais, a diluição do ônus reparatório na sociedade" (SCHREIBER, 2012, p. 235).

Glenda Gonçalves Gondim (2015, p. 147) identifica, nesse sentido, um sistema "bifronte" de responsabilidade civil, devendo haver a coexistência da prevenção com a imputação:

Como a proposta inicial é o não resultado dano, podem ser imputadas respostas para evitar que ele venha a ocorrer, dentro da análise do comportamento contrário ao Direito. Caso venha a resultar o dano, será analisado se é preciso uma medida para evitar que ele continue a ocorrer, no sentido de cessar a lesão, dentro desta concepção será analisada as duas vertentes de comportamento e da consequência dano. Por fim, em caso de ocorrência de dano, que não tem caráter de continuidade, a resposta jurídica deverá ser adotada dentro da noção de reparar.

Pois bem. A responsabilidade civil fundada em suas funções clássicas (reparatória, sancionatória e dissuasória) tem caminhado para uma imputabilidade absoluta por meio de vertentes extremadas da teoria do risco. A despeito do que há de sedutor nos programas de socialização dos riscos, o princípio da responsabilidade civil deve sobreviver e individualizar a obrigação de reparação em diversos cenários, particularmente nos que infringem vultosos danos à sociedade em decorrência de atividades de risco. A principal dessas vertentes é a teoria do risco integral, assim definida por Sergio Cavalieri Filho (2014, p. 184):

\footnotetext{
$\mathrm{Na}$ responsabilidade fundada no risco integral, o dever de indenizar é imputado àquele que cria o risco, ainda que a atividade por ele exercida não tenha sido a causa direta e imediata do evento. Bastará que a atividade de risco tenha sido a ocasião, mera causa mediata ou indireta do evento, ainda que este tenha tido por causa direta e imediata fato irresistível ou inevitável, como a força maior e o caso fortuito. Em outras palavras, o dano não é causado diretamente por uma atividade de risco, mas seu exercício é a ocasião para a ocorrência do evento.
}

Nota-se que o autor destaca como singularidade do risco integral a mudança de perspectiva em relação ao nexo causal, dispensando sua análise baseada no corriqueiro prisma da causalidade direta e imediata, ou da causalidade adequada. O redirecionamento da ótica sob a qual o nexo de causalidade é examinado - resultado de uma temperança (SCHREIBER, 2012, p. 66) entre as teorias causais da conditio sine qua non e da violação ao escopo da norma (SILVESTRE; MILL, 2021, p. 150-157) — implica, sem dúvida, a 
flexibilização desse elemento, a fim de ser assegurada às vítimas a máxima reparação dos danos injustamente sofridos (SCHREIBER, 2012, p. 78).

O progresso científico, tecnológico e econômico experimentado na segunda metade do século passado inaugurou uma era em que bens de titularidade coletiva ou difusa são permanentemente ameaçados. Pode-se dizer que o principal deles é o meio ambiente, constantemente impactado por mineração em larga escala, extração de petróleo marinho, geração de energia nuclear, dentre outros potenciais focos poluidores. Não à toa, estabeleceuse no ordenamento jurídico brasileiro o postulado do poluidor-pagador, cuja máxima é a de que aquele que polui — intencionalmente ou não — deve arcar com as consequências decorrentes da atividade, imputando-lhe o ônus financeiro de diminuição ou afastamento dos danos.

A literatura jurídica e a jurisprudência, então, não elaborariam uma teoria do risco quase que universalmente abrangente, com o propósito resumido a tutelar os interesses dos vulneráveis às atividades econômicas e políticas contemporâneas; afinal, "the tortfeasor, whether his liability is based on fault or is strict, is regarded as having exposed society to certain dangers of harm (risks). If harm occurs of which his conduct is a condition, he is liable provided the harm falls within the risks to which he has exposed others" (HONORÉ, 1983, p. 58 apud FACCHINI NETO, 2016, p. 8). Julio Alberto Díaz (1998, p. 121) acrescenta que "a responsabilidade não pode se basear em um mero estar no lugar dos acontecimentos. Essa presença deve revelar um certo compromisso eficiente com o perigo que surge da fonte comunitária". Com efeito, os obrigados pela reparação devem estar vinculados por circunstâncias de tempo, ou de lugar, relevantes, de modo que arquem conjuntamente com a situação de risco (PEREIRA, 2006, p. 187).

Desse modo, a responsabilidade civil fundada no risco integral se baseia na internalização dos riscos conexos e inerentes à atividade de risco, devendo o ente público ou particular absorver os danos e promover as mais diversas ações reparatórias - pecuniárias ou não. Prioriza-se a reparação do cenário lesivo causado, centrando a imputação em quem primariamente proporcionou as condições para que tais danos se consumassem - preservada a possibilidade de ação regressiva (BENJAMIN, 1998, p. 41).

Estabelecido o liame causal entre o fato e o agente, dificilmente será assentida a exclusão da responsabilidade por fato de terceiro, culpa da vítima ou caso fortuito, acolhida pelos tribunais apenas em situações excepcionais e sob patente demonstração de rompimento 
do nexo de causalidade. Tem-se, portanto, o cenário da imputabilidade absoluta ao qual chegou a responsabilidade civil em suas funções tradicionais.

\section{Análise de julgados: a responsabilidade civil preventiva e teoria do risco integral em instâncias de apelação e superior}

O tratamento conferido à responsabilidade preventiva nos moldes aqui defendidos é amplo no que toca ao direito ambiental, sendo o princípio da precaução, inclusive, um dos baluartes dessa disciplina. É extenso, também, no direito antitruste (concorrencial), em que a precaução também é frequentemente suscitada em decisões do Conselho Administrativo de Defesa Econômica (Cade) (FIGUEIREDO, 2014, p. 106-107).

Ainda é incipiente sua ocorrência no direito privado para a jurisprudência brasileira — ao menos no que diz respeito à responsabilidade objetiva extracontratual —, mas é possível identificar julgados que, amparados em normas atinentes ao direito vicinal, ou mesmo diretamente a direitos da personalidade, adotam uma postura de responsabilidade civil preventiva, sempre destacando o risco como algo hábil a ser confrontado, ou seja, como fator de imputação da responsabilidade (SANTOLIM, 2014, p. 8. 444).

Um exemplo é o julgamento do recurso de apelação $n^{\circ}$ 1001033-45.2013.8.26.0198, que tramitou na $31^{\text {a }}$ Câmara de Direito Privado do Tribunal de Justiça do Estado de São Paulo. Diante de uma ação de obrigação de fazer, proposta por pessoa física em face de uma empresa de transportes, restou consignado que "há efetivo risco de dano ao imóvel da autora ante o porte avantajado das árvores plantadas no imóvel da recorrente na área limítrofe do imóvel da apelada", implicando a manutenção da sentença que havia condenado a empresa-ré à "obrigação de fazer consistente em realizar, no prazo de 60 (sessenta) dias, a remoção dos exemplares de árvores de grande porte (eucaliptos) junto ao muro e próximos à residência da requerente, que deverão ser substituídos por exemplares de menor porte". 9 Trata-se claramente de uma tutela ex ante, concedida antes da consumação dos potenciais danos materiais que a circunstância apresentava.

No que toca ao resguardo aos direitos da personalidade, vê-se recente julgado da $16^{\mathrm{a}}$ Câmara Cível do Tribunal de Justiça do Estado de Minas Gerais ${ }^{10}$ em caso relativo a

\footnotetext{
${ }^{9}$ TJ-SP - Apelação cível no $1001033-45.2013 .8 .26 .0198,31^{\text {a }}$ Câmara de Direito Privado, Rel Des. Paulo Celso Ayrosa, Data de Julgamento: 25.01.2019.

${ }^{10}$ TJ-MG - Apelação cível no 0040923-73.2016.8.13.0324, 16 Câmara Cível, Rel. Des. José Marcos Vieira, Data de Julgamento: 10.04.2019.
} 
mecanismos de busca de processos criminais em provedores de pesquisa online. $\mathrm{O}$ autor visava à desindexação de seu nome de condenação criminal sofrida e já cumprida há oito anos, em uma espécie de "direito ao esquecimento" em face das plataformas privadas Jusbrasil e Google. O relator, em seu voto, relaciona o caso - direito à privacidade prevalecendo sobre o direito à informação — à conjuntura da sociedade de riscos, dando enfoque às relações privadas:

É sabido que, na atualidade, por força de vertiginosos avanços tecnológicos, instituições estatais e privadas têm condições de obter, armazenar, tratar e divulgar uma quantidade de informações sobre as pessoas que era impensável no passado, o que aumenta a vulnerabilidade dos indivíduos. Fazemos compras, lemos textos e notícias, nos comunicamos com o mundo e conduzimos as nossas atividades cotidianas por meios eletrônicos. O uso disseminado em todo o mundo da Internet e das redes sociais permite que sejam armazenadas informações pessoais, mensagens privadas, fotografias, dados sobre os hábitos de busca e navegação e muitos outros elementos, que podem ser utilizados de forma ilegítima, violando direitos humanos. A possibilidade de vigilância total e permanente sobre o indivíduo, com graves riscos à sua personalidade, saiu do terreno da ficção para entrar na realidade, como se tem verificado na atuação de diversos Estados após o atentado às torres gêmeas. $\mathrm{E}$ não é só do Estado que vem a ameaça. Como observou Laura Schertel Mendes, o risco hoje "não se restringe mais à figura do 'Big Brother' de Orwell, mas abrange também o setor privado, que utiliza massivamente os dados pessoais para atingir seus objetivos econômicos".

Sendo assim, conquanto não haja pleito indenizatório ou menção a danos plenamente consumados, percebe-se uma tutela preventiva positiva que afasta o risco de perturbações aos direitos da personalidade do autor. A conduta dos provedores demandados foi inibida com espeque na demonstração do nexo causal entre a conduta e o contexto potencialmente danoso ao qual foi submetido o particular.

Já a temática ambiental oferece tanto uma face pública — proteção ao meio ambiente propriamente dito, i.e., o meio ambiente ecologicamente equilibrado como um bem de titularidade coletiva-difusa - quanto uma face privada, em que se tutelam os danos causados pela degradação ambiental à esfera privada, ou seja, danos ambientais que afetam "em ricochete" bens de titularidade individual (MIRRA, 2004, p. 76-77). Em ambas, para além do princípio da precaução, observa-se a imputabilidade absoluta por meio da aplicação do risco integral, conforme visto no recurso de apelação $n^{\circ}$ 0016231-76.2012.8.08.0069, julgado pelo Tribunal de Justiça do Estado do Espírito Santo: ali, assentou-se que a responsabilidade civil é objetiva e se funda na teoria do risco integral, bastando "a comprovação da existência de nexo de causalidade entre os efeitos danosos e o comportamento comissivo ou omissivo que, direta 
ou indiretamente, causou a degradação”. Deduz-se, assim, que a imputabilidade absoluta opera por meio do redirecionamento da ótica sob a qual é examinado o nexo causal, ótica essa diversa das teorias causais corriqueiramente empregadas no ordenamento jurídico brasileiro: a teoria da causalidade adequada e a teoria do dano direto e imediato (SILVESTRE; MILL, 2021, p. 148-149).

Na mesma linha, o Superior Tribunal de Justiça, em julgados que suscitam o risco integral no contexto de danos ambientais, destaca a releitura do nexo causal como método de operabilidade do raciocínio. No REsp $\mathrm{n}^{\circ}$ 1.374.284/MG, que tratava do pleito indenizatório de uma vítima de enchentes decorrentes do vazamento de lama tóxica proveniente de atividade minerária, a mineradora alegou a ocorrência de fortes chuvas na região em que mora a vítima, o que teria provocado as enchentes causadoras dos danos em questão - rompendo, assim, o nexo causal entre a lesão e a atividade da empresa. Seguindo precedente firmado no REsp $n^{\circ}$ 1.114.398/PR, julgado sob a sistemática dos recursos repetitivos (CPC/15, art. 1.036), o relator, Min. Luis Felipe Salomão, afirmou que a responsabilidade por dano ambiental se embasa na teoria do risco integral, sendo

[...] o nexo de causalidade o fator aglutinante que permite que o risco se integre na unidade do ato que é fonte da obrigação de indenizar, de modo que, aquele que explora a atividade econômica coloca-se na posição de garantidor da preservação ambiental, e os danos que digam respeito à atividade estarão sempre vinculados a ela.

Em seguida, inferiu que "constatou-se a existência de uma relação de causa e efeito, verdadeira ligação entre o rompimento da barragem com o vazamento de 2 (dois) bilhões de litros de dejetos de bauxita - corroborando para o transbordamento do rio Muriaé —, e o resultado danoso com a inundação da casa da recorrida contendo o referido mineral. Diante disso, constatado o nexo causal, não há mais, em sede de especial, como se discutir a ocorrência ou não de referido requisito".

O raciocínio empreendido, no sentido de identificar uma ligação entre o dano e a atividade de risco e de nisto fundamentar o nexo causal — vínculo "aglutinante" entre a lesão sofrida e a atividade condicionante de tal lesão —, remete à qualificação de todas as condições para o resultado danoso como causas — ideia ligada à equivalência das condições —, bem como à opção valorativa de se imputar a responsabilidade civil ao executor da atividade de extremo risco, condição primeira para o evento indenizável. Destarte, não se 
admitem as causas excludentes de responsabilidade apenas pelo fato de existirem outras condições para a consumação daquele dano. Para Annelise Monteiro Steigleder, Édis Milaré e Paulo Affonso Leme Machado (2011, p. 43-48), o risco integral "não admite excludentes de responsabilidade, tais como o caso fortuito, a força maior, a ação de terceiros ou da própria vítima, posto que tais acontecimentos são considerados ‘condições' do evento”.

\section{Conclusão}

A responsabilidade civil tem se transformado em relação às suas funções tradicionais, apresentando, contemporaneamente, (i) uma vertente preventiva, distante da reprimenda a posteriori que tem como fim precípuo a reparação de um dano já integralmente consumado, e perquirindo, assim, uma tutela positiva ex ante; e (ii) um agravamento da vertente reparadora, simbolizado sobretudo pela teoria do risco integral, que pressupõe, mediante releitura do nexo de causalidade, a internalização dos riscos conexos à atividade de risco intolerável.

Desse modo, a tutela ex ante visa à ampliação da segurança e ao controle dos riscos, mostrando-se uma alternativa jurídica e administrativa pragmática para fins acautelatórios, ainda que esteja presente o risco residual - o qual, por sua vez, exige o aprimoramento da responsabilidade civil em suas funções tradicionais.

Tal aprimoramento se funda na teoria no risco integral, uma face extremada da responsabilidade civil objetiva que estabelece a internalização dos riscos conexos e inerentes à atividade de risco, devendo o ente público ou particular absorver os danos e promover as mais diversas ações reparatórias - pecuniárias ou não. Prioriza-se a reparação do cenário lesivo causado, centrando a imputação em quem primariamente proporcionou as condições para que tais danos se consumassem, preservada a possibilidade de ação regressiva.

Determinado, então, o nexo causal entre o fato e o agente, dificilmente será assentida a exclusão da responsabilidade por fato de terceiro, culpa da vítima ou caso fortuito, acolhida pelos tribunais apenas em situações excepcionais e sob patente demonstração de rompimento do vínculo de causalidade.

\section{Referências bibliográficas}


ALBUQUERQUE JR., Roberto Paulino de. Notas sobre a teoria da responsabilidade civil sem dano. In: Revista de Direito Civil Contemporâneo, São Paulo, v. 6, ano 3, p. 89-103, jan./mar., 2016.

ALMEIDA COSTA, Mário Júlio. Direito das Obrigações. $8^{a}$ ed., Coimbra: Almedina, 2000.

ALTERINI, Atilio Anibal. Responsabilidad civil. Buenos Aires: Abeledo-Perrot, 1974.

BECK, Ulrich. Sociedade de risco: rumo a uma outra modernidade. $2^{\text {a }}$ ed., São Paulo: Ed. 34, 2011.

BENJAMIN, Antonio Herman V.. Responsabilidade civil pelo dano ambiental. In: Revista de Direito Ambiental, São Paulo, v. 3, n. 9, jan./mar., 1998.

BINENBOJM, Gustavo. Poder de polícia, ordenação, regulação: transformações políticojurídicas, econômicas e institucionais do direito administrativo ordenador. $2^{\text {a }}$ ed., Belo Horizonte: Fórum, 2017.

CARRÁ, Bruno Leonardo Câmara. É possível uma responsabilidade civil sem dano? (I). In: Consultor Jurídico, acesso em 22.07.2019. Disponível em: https://www.conjur.com.br/2016-abr-18/direito-civil-atual-possivel-responsabilidade-civildano.

CAVALIERI FILHO, Sergio. Programa de responsabilidade civil. $11^{\mathrm{a}}$ ed., São Paulo: Atlas, 2014.

DIAS, José de Aguiar. Da responsabilidade civil. $7^{\text {a }}$ ed., Rio de Janeiro: Forense, v. 2, 1983. FACCHINI NETO, Eugênio. Da responsabilidade civil no novo Código. In: SARLET, Ingo Wolfgang (Org.). O novo Código Civil e a Constituição. Porto Alegre: Livraria do Advogado, 2003.

A relativização do nexo de causalidade e a responsabilização da indústria do fumo: a aceitação da lógica da probabilidade. In: civilistica.com, ano 5, n. 1, 2016.

FALBO, Ricardo Nery; KELLER, René José. Sociedade de risco: avanços e limites da teoria de Ulrich Beck. In: Quaestio Juris, Rio de Janeiro, v. 8, n. 3, 2015.

FIGUEIREDO, Natália de Lima. Poder da Marca: interações entre direito antitruste e direito industrial. Dissertação (Mestrado em Direito) — Faculdade de Direito da Universidade de São Paulo, São Paulo, 2014.

GIANESINI, Rita. Ação de nunciação de obra nova. São Paulo: Revista dos Tribunais, 1993. 
GODIM, Glenda Gonçalves. Responsabilidade civil sem dano: da lógica reparatória à lógica inibitória. Tese (Doutorado em Direito) - Curso de pós-graduação em Direito, Setor de Ciências Jurídicas da Universidade Federal do Paraná, Curitiba, 2015.

HIRONAKA, Giselda Maria Fernandes Novaes. Responsabilidade pressuposta: evolução de fundamentos e de paradigmas da responsabilidade civil na contemporaneidade. In: Revista da Faculdade de Direito da UFG, v. 31, n. 1, p. 33-59, 2007.

KOURILSKY, Philippe; VINEY, Geneviève. Le princip de précaution: rapport au Premier Ministre. Paris: Odile Jacob - La Documentation française, 2000.

LIMA, Alvino. Culpa e risco. $2^{\mathrm{a}}$ ed., São Paulo: Revista dos Tribunais, 1998.

LOPEZ, Teresa Ancona. Responsabilidade civil na sociedade de risco. In: Revista da Faculdade de Direito da Universidade de São Paulo, v. 105, p. 1.223-1.234, jan./dez., 2010.

MARTINS-COSTA, Judith; PARGENDLER, Mariana Souza. Usos e abusos da função punitiva. In: Revista da AJURIS, Porto Alegre, v. 32, n. 100, 2005.

MIRRA, Álvaro Luiz Valery. Ação civil pública e a reparação do dano ao meio ambiente. $2^{a}$ ed., São Paulo: Juarez de Oliveira, 2004.

NORONHA, Fernando. Direito das Obrigações. $4^{a}$ ed., São Paulo: Saraiva, 2013.

PEREIRA, Alexandre Pimenta Batista. Os confins da responsabilidade civil objetiva nos horizontes da sociedade de risco. Almejando a permanente certeza na contingência das improbabilidades. In: Revista de Informação Legislativa, Brasília, v. 43, n. 170, p. 181-189, abr./jun., 2006.

PEREIRA, Caio Mário da Silva. Responsabilidade civil. 12 ${ }^{\mathrm{a}}$ ed., Rio de Janeiro: Forense, 2018.

PONZANELLI, Giulio. La Responsabilità Medica ad un Bivio: Assicurazione Obbligatoria, Sistema Residuale No-Fault o Risk Management?. In: Danno e Responsabilità, n. 4, 2003.

SANSEVERINO, Paulo de Tarso Vieira. Princípio da reparação integral: indenização no Código Civil. São Paulo: Saraiva, 2010, p. 58.

SANTOLIM, Cesar. Nexo de causalidade e prevenção na responsabilidade civil no Direito brasileiro e português. In: Revista do Instituto de Direito Brasileiro, ano 3, n. 10, 2014.

SCHREIBER, Anderson. Novos paradigmas da responsabilidade civil. $4^{\text {a }}$ ed., São Paulo: Atlas, 2012. 
SILVESTRE, Gilberto Fachetti; MILL, Lorenzo Caser. A compostura entre a teoria da conditio sine qua non e a teoria do escopo da norma: a peculiaridade brasileira da teoria do risco integral na responsabilidade civil objetiva. In: Revista de Direito Privado, ano 22, v. 108, abr./jun., p. 141-161, 2021.

SINTEZ, Cyril. La sanction préventive en droit de la responsabilité civile: contribution à la theorie de l'interprétation et de la meise en effet des normes. Paris: Dalloz, 2011.

STARCK, Boris. Essai d'une théorie générale de la responsabilité civile considérée en sa double fonction de garantie et de peine privée. Paris: L. Rodstein, 1947.

STEIGLEDER, Annelise Monteiro, MILARÉ, Édis; MACHADO, Paulo Affonso Leme (Orgs.). In: Doutrinas essenciais de direito ambiental: responsabilidade em matéria ambiental. São Paulo: Revista dos Tribunais, v. 5, 2011.

VAZ, Caroline. Funções da responsabilidade civil: da reparação à punição e dissuasão. Os punitive damages no Direito Comparado e Brasileiro. Porto Alegre: Livraria do Advogado, 2009.

WEDY, Gabriel. O princípio da precaução e a responsabilidade civil do Estado. In: Revista da AJURIS, v. 41, n. 134, Junho, 2014. 